\title{
Impaired oxidation of debrisoquine in patients with perhexiline neuropathy
}

\author{
R R SHAH, N S OATES, J R IDLE， R L SMITH，J D F LOCKHART
}

\begin{abstract}
The use of perhexiline maleate as antianginal agent is occasionally associated with side effects, particularly neuropathy and liver damage. The reason why some individuals develop these toxic reactions is not clear, though some evidence suggests that they may result from impaired oxidative metabolism, due to genetic or hepatic factors, and consequential accumulation of the drug in toxic concentrations. Drug oxidation was measured with an oxidation phenotyping procedure in 34 patients treated with perhexiline, 20 of whom had developed neuropathy and 14 of whom had not. Most of the 20 patients with neuropathy, but not the unaffected patients, showed an impaired ability to effect metabolic drug oxidation. This impairment was independent of hepatic function, concurrent drug therapy, or tobacco or alcohol consumption.

The fact that the ability to oxidise several drugs is genetically controlled points to a genetic susceptibility to developing neuropathy in response to perhexiline. Routine determination of the drug oxidation phenotype might lead to safer use of perhexiline by predicting patients who may be more at risk of developing a neuropathic reaction associated with its long-term use.
\end{abstract}

\section{Introduction}

Perhexiline maleate (Pexid), a synthetic antianginal agent, was first marketed in the UK in 1975. Clinical trials have shown its

\footnotetext{
Department of Biochemical and Experimental Pharmacology, St Mary's Hospital Medical School, London W2 1PG

R R SHAH, BSC, MRCP, Wellcome clinical research fellow N S OATES, PHD, Wellcome research fellow

J R IDLE, PHD, lecturer in biochemical pharmacology

R L SMITH, DSC, PHD, professor of biochemical pharmacology

Merrell Pharmaceuticals Limited, Hounslow, Middlesex TW5 9QY J D F LOCKHART, MB, DPH, director of clinical studies
}

efficacy in reducing both anginal attacks and the consumption of glyceryl trinitrate in patients with myocardial ischaemia. ${ }^{1-3}$ Its mode of action is not fully understood, but it reduces exerciseinduced tachycardia and improves exercise tolerance without effect on blood pressure or resting heart rate. ${ }^{4}$. It has calcium antagonistic properties ${ }^{6}$ and may exert some intracellular biochemical effect to reduce high-peak demand for oxygen during exercise or stress. ${ }^{?}$

The use of perhexiline has, however, become increasingly associated with adverse effects, both minor and major. The minor side effects, which include nausea, vomiting, dizziness, lethargy, insomnia, tremor, and loss of libido, ${ }^{8-11}$ have not been too troublesome, and if they do not disappear spontaneously, ${ }^{9} 11$ they can easily be controlled by reducing the dose or stopping the drug. ${ }^{8} 9$ The major side effects comprise peripheral neuropathy ${ }^{12}{ }^{13}$; hepatic damage, ${ }^{1415}$ including cirrhosis ${ }^{16}$; hypoglycaemia ${ }^{17}$; and weight loss. $^{8}{ }^{9}$ Proximal myopathy ${ }^{18}$ and papilloedema $a^{19: 0}$ have also been reported. Most of these effects are reversed when the drug is withdrawn, but the return of neurological and hepatic functions to normal may be slow or incomplete.

The reason why some people develop serious toxic reactions to perhexiline is not clear, though some evidence suggests that the reactions may result from impaired metabolism of the drug. Perhexiline is a lipophilic drug and its elimination depends on metabolic oxidation to the more polar monohydroxylated and dihydroxylated metabolites. The large interindividual variations in plasma half lives of perhexiline have been interpreted as being due to interindividual differences in the rate of metabolism of the drug. ${ }^{21}$ L'Hermitte et al suggested that perhexiline-induced neuropathy might represent individual susceptibility, perhaps secondary to some latent inborn metabolic disorder, ${ }^{22}$ and Singlas et al later showed that patients with peripheral neuropathy had higher perhexiline plasma concentrations and longer plasma half lives than those without peripheral neuropathy. ${ }^{23}$ Furthermore, the mean ratio of plasma concentrations of the parent drug to those of its major metabolite, monohydroxy-perhexiline, was some nine times higher in the patients with neuropathy than in the controls, and they concluded that this toxic effect of perhexiline was associated with accumulation of the parent drug due to different patterns of distribution or metabolism in affected individuals. ${ }^{23}$ The metabolic differences, in turn, were attributed 
ability to oxidise several other drugs besides debrisoquine. ${ }^{25} 2728$ This genetic polymorphism in drug oxidation reactions has several important implications. One of the more significant is that in subjects with impairment drugs that are normally eliminated by oxidation are more likely to accumulate, possibly to toxic concentrations. ${ }^{29}$

We therefore investigated patients who had developed perhexiline-induced neuropathy for their debrisoquine oxidation status on the supposition that the toxicity could be the result of an impaired ability to eliminate drugs through oxidation.

\section{Patients and methods}

Twenty patients with past or present perhexiline-induced neuropathy confirmed by nerve conduction studies (18) or definite clinical evidence (2), were identified from various cardiac outpatient departments. Another 14 patients who received perhexiline for angina and who had had no serious side effects on long term treatment served as controls. A further 38 patients with ischaemic heart disease who had never had perhexiline were also included in the study to assess the influence of the disease on oxidation pattern and also to determine whether the disease had predilection for any particular oxidation status. Approval was obtained from the St Mary's Hospital ethical committee, and each patient gave his or her informed consent before participating in the study. The details of these patients and, where appropriate, the approximate weekly intake of perhexiline are given in table I.

All the patients were phenotyped for oxidation status, ${ }^{24}$ and each took a single 10-mg oral dose of debrisoquine (Declinax 10, Roche). The urine passed in the subsequent eight hours was collected in bulk, the volume measured, and a $20-\mathrm{ml}$ sample stored at $-20^{\circ} \mathrm{C}$ before analysis. Each sample was analysed for its content of parent drug and its major metabolite, 4-hydroxy-debrisoquine using electroncapture gas chromatography. From the results, the metabolic ratio was calculated. This ratio defines an individual's ability to metabolise debrisoquine (and by inference several other drugs) and is derived as follows:

\section{$\%$ dose excreted as unchanged debrisoquine \\ $\%$ dose excreted as 4-hydroxy-debrisoquine}

after a single 10 -mg oral dose of the drug. Low values $(<1)$ represent extensive oxidative ability, while values greater than 12.6 indicate the grossly impaired ability found in the individuals homozygous for the $\mathrm{D}^{1}$ allele. ${ }^{26}$ Intermediate ratios indicate varying degrees of impairment.

To assess their hepatic function, routine biochemical liver function tests were carried out on all the patients included in this study. Most of these tests were performed within one week of the debrisoquine phenotyping test.

\section{Results}

Table I shows the details of the 34 patients who received long-term perhexiline treatment for angina, together with the results of their liver function tests and their debrisoquine metabolic ratios. The 20 patients who developed neuropathy consisted of $18 \mathrm{men}$ and 2 women while the 14 patients who did not develop this complication included 10 men and 4 women. There were no significant differences between the two groups in terms of their age, weight, or alcohol consumption. Ten of the 20 neuropathic patients and two of the 14 non-neuropathic individuals consumed tobacco in some form. Both groups were exposed to comparable dosages of perhexiline. In the eight hours the mean ( $\perp \mathrm{SD}$ ) urinary recoveries of debrisoquine plus 4-hydroxydebrisoquine were $29 \cdot 8 \pm 13.1 \%$ (range $14-67 \%$ ) in the neuropathic group and $26 \cdot 1 \pm 10 \cdot 7 \%$ (range $12-53 \%$ ) in the non-neuropathic group. The patients fell into two fairly well defined groups with respect to their oxidation status and the development of neuropathy.

The patients who developed neuropathy showed metabolic ratios in the range $0 \cdot 5->100$ with a median value of 14.4 whereas the range for the non-neuropathic group was 0.4-4.6 with a median value of 0.65 . The median metabolic ratio of the neuropathic group was significantly greater than that of the non-neuropathic group as determined by the Wilcoxon rank test. There were many more patients with ratios of more than $12.6(50 \%)$ and fewer with ratios of less than $1.0(15 \%)$ among those who developed neuropathy. This preponderance of individuals with high metabolic ratios was significantly greater $\left(\chi^{2}=\right.$
$37.9 ; \mathrm{p}<0.0001)$ in the neuropathy group than would have been expected in normal healthy population ${ }^{24} 26$ or in a random sample of patients with ischaemic heart disease (see below). Correspondingly, the neuropathy group contained significantly fewer $\left(\chi^{2}=7 \cdot 6, p<0 \cdot 01\right)$ individuals with metabolic ratios of less than 1.0 .

Table I also shows details of the 38 patients ( 35 men and 3 women) with ischaemic heart disease who were not prescribed perhexiline and the results of their liver function tests and debrisoquine metabolic ratios. This group of patients did not differ in age, weight, alcohol or tobacco consumption, or biochemical liver function values from the two perhexiline-treated groups. Their mean eight-hour urinary recovery of debrisoquine plus 4-hydroxy-debrisoquine $(33.9 \pm 9.3 \%$, range $11-62^{\circ}$ ) was also comparable. These patients had metabolic ratios of 0.1-39 with a median value of $0 \cdot 55$. Only three patients had a ratio greater than $12 \cdot 6(8 \%)$, whereas 25 had a ratio of less than $1.0(66 \%)$. The remaining 10 patients $(26 \%)$ had intermediate ratios.

\section{Discussion}

The question arises whether the metabolic impairment in the neuropathic patients was due to hepatic dysfunction produced by perhexiline treatment. It is impossible to generalise about the effect of liver dysfunction on drug oxidation since the findings are inconsistent and sometimes contradictory..$^{30}$ Thus, the rate of metabolism of phenylbutazone, ${ }^{31}$ aminopyrine, ${ }^{32}$ bishydroxycoumarin,$^{32}$ antipyrine, ${ }^{33}$ tolbutamide, ${ }^{33}$ and pentobarbital ${ }^{34}$ were not significantly changed, while other investigations have shown the half lives of phenylbutazone ${ }^{35}$ and meprobamate ${ }^{36}$ to be prolonged in patients with liver dysfunction. A leading article in the Lancet $^{37}$ concluded that even patients with advanced chronic liver disease metabolise drugs surprisingly normally. There was no significant difference between our three groups in their various liver function values. In the 72 patients investigated there was no correlation between the measured metabolic ratios and any of the liver function values. Therefore the difference in debrisoquine metabolic ratios between the two perhexiline-treated groups of patients probably did not originate in hepatic dysfunction. Furthermore, we have found in unpublished studies that the metabolic ratio for debrisoquine is unaffected by mild-to-moderate hepatic damage unless accompanied by hyperbilirubinaemia. Similarly, no difference was discernible between the two groups of patients on perhexiline in terms of their smoking habits or alcohol consumption.

All except four of the perhexiline-treated patients had discontinued perhexiline at least four weeks before being phenotyped. The concurrent drug treatment of all the patients studied at the time of the assessment of their oxidation status is shown in table II. It may be suggested that certain drugs when taken concurrently may influence each other's metabolic fate and therefore that the metabolic ratios of patients with neuropathy may be artefactually raised. Evidence against this suggestion is provided by our group of 38 patients with ischaemic heart disease. The pattern of drug treatment in this group was similar to that in the two perhexiline-treated groups (table II); they had metabolic ratios in the range of $0 \cdot 1-39$ and a median metabolic ratio of 0.55 , which was lower than that of normal healthy population $(0 \cdot 8)$ receiving no medication. The proportion of individuals with metabolic ratios greater than $12.6(7.9 \%)$ among these 38 patients was also close to that in healthy population. ${ }^{26}$ Therefore the reason for the pronounced differences in the distribution of the metabolic ratios between the neuropathy group compared and the other two groups was not the result of concurrent drug treatment.

These results show a clear association between the occurrence of perhexiline-induced neuropathy and diminished drug metabolic ability as shown by debrisoquine hydroxylation. They suggest that individuals of poor metaboliser phenotype are at greater risk of developing neuropathy from long-term perhexiline therapy. This risk is strikingly reduced in extensive metabolisers who have metabolic ratios of less than 1 .

The association between diminished drug oxidation status and propensity to develop a neuropathic reaction to perhexiline 
makes it plausible to suggest that perhexiline would tend to accumulate in individuals with impaired drug oxidising ability because of defective metabolic elimination. The accumulation of the parent drug may then produce toxic sequelae. The mechanism of these toxic reactions is unknown, but drug-induced disturbances of lipid metabolism have been implicated. ${ }^{38}$

Without any obvious causes three of our 20 patients developed neuropathy despite their metabolic ratios being less than 1 . It therefore seems likely that, although an individual's drug oxidation status may be a major pharmacokinetic determinant of drug response (toxic or therapeutic), other, as yet unidentified, factors may also contribute to producing toxic sequelae in a few patients. Such factors may include disorders affecting the

TABLE II-Details of concurrent drug therapy in 34 perhexiline-treated patients at the time of phenotyping and in 38 patients who had never received perhexiline

\begin{tabular}{|c|c|}
\hline \multicolumn{2}{|c|}{$\begin{array}{l}\text { Case No } \\
\text { (metabolic ratio) }\end{array}$} \\
\hline \multicolumn{2}{|r|}{ Patients treated with perhexiline } \\
\hline \multicolumn{2}{|l|}{$\begin{array}{l}\text { Neuropathic } \\
\text { patients }\end{array}$} \\
\hline $1(0 \cdot 5)$ & Frusemide, nitrates, potassium supplements \\
\hline $\begin{array}{l}2(0 \cdot 8) \\
3(0 \cdot 9)\end{array}$ & Propranolol, nifedipine \\
\hline $\begin{array}{l}3(0 \cdot 9) \\
4(1 \cdot 6)\end{array}$ & $\begin{array}{l}\text { Propranolol, nifedipine, digoxin } \\
\text { Metoprolol, frusemide, potassium supplements }\end{array}$ \\
\hline $5(2 \cdot 6)$ & Nitrates \\
\hline $6(2 \cdot 6)$ & Warfarin, salbutamol, thiazide, spironolactone \\
\hline $\begin{array}{l}7(4 \cdot 5) \\
8(5 \cdot 7)\end{array}$ & Nifedipine \\
\hline $\begin{array}{l}8(5 \cdot 7) \\
9(8 \cdot 5)\end{array}$ & $\begin{array}{l}\text { Atenolol, niredipine, nitrates, wartarin, dipyridamole } \\
\text { Propranolol }\end{array}$ \\
\hline $10(10)$ & Oxprenolol, thiazide, potassium supplements \\
\hline $11(19)$ & Atenolol, perhexiline, nitrates \\
\hline $12(25)$ & Propranolol \\
\hline $\begin{array}{l}13(27) \\
14(28)\end{array}$ & $\begin{array}{l}\text { Acebutolol, thiazide, potassium supplements } \\
\text { None }\end{array}$ \\
\hline $15(30)$ & Oxprenolol, metformin, chlorpropamide \\
\hline $16(32)$ & Metoprolol, thiazide, amiloride \\
\hline $17(35)$ & Oxprenolol, perhexiline \\
\hline $\begin{array}{l}18(69) \\
19(77)\end{array}$ & $\begin{array}{l}\text { Metoprolol } \\
\text { Propranolol, nifedipine, thiazide, amiloride }\end{array}$ \\
\hline $20(>100)$ & Dipyridamole, theophylline, chlordiazepoxide, cinnarizine \\
\hline \multicolumn{2}{|c|}{ Non-neuropathic } \\
\hline $21(0 \cdot 4)$ & None \\
\hline $22(0.4)$ & Nitrates, frusemide, spironolactone \\
\hline $23(0.5)$ & Atenolol, nifedipine, frusemide, potassium supplements \\
\hline $\begin{array}{l}24(0.5) \\
25(0.6)\end{array}$ & $\begin{array}{l}\text { Aspirin, allopurinol, dipyridamole } \\
\text { Digoxin, perhexiline, nitrates, thiazide, potassium supplements }\end{array}$ \\
\hline $26(0.6)$ & Metoprolol, nitrates, triamterene \\
\hline $27(0 \cdot 6)$ & Nitrates \\
\hline $28(0.7)$ & $\begin{array}{l}\text { Bumetanide, potassium supplements, phenytoin, phenobarbitone, } \\
\text { salbutamol, naproxen }\end{array}$ \\
\hline \multirow{6}{*}{$\begin{array}{l}29(1 \cdot 0) \\
30(1 \cdot 1) \\
31(1 \cdot 1) \\
32(1 \cdot 6) \\
33(1 \cdot 7) \\
34(4 \cdot 6)\end{array}$} & Propranolol, thiazide, potassium supplements \\
\hline & Propranolol, nitrates, thiazide, potassium suppl \\
\hline & $\begin{array}{l}\text { Propranolol, nifedipine, allopurinol } \\
\text { Triamterene, oxazepam }\end{array}$ \\
\hline & Perhexiline \\
\hline & Metoprolol, perhexiline, nitrates \\
\hline & Patients who never received perhexiline \\
\hline $\begin{array}{l}35(0 \cdot 1) \\
36(0 \cdot 1)\end{array}$ & $\begin{array}{l}\text { Nitrates, thiazide, frusemide, potassium supplements } \\
\text { Thyroxine, dipyridamole }\end{array}$ \\
\hline $37(0 \cdot 1)$ & 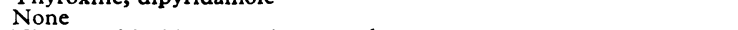 \\
\hline $38(0 \cdot 2)$ & Nitrates, thiazide, potassium supplements \\
\hline $39(0 \cdot 2)$ & Digoxin, metoprolol, warfarin \\
\hline $40(0 \cdot 2)$ & None. \\
\hline $41(0 \cdot 2)$ & Digoxin, frusemide, spironolactone, tetracycline \\
\hline $42(0 \cdot 2)$ & 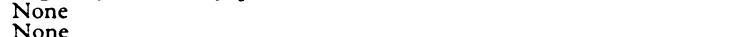 \\
\hline $\begin{array}{l}43(0 \cdot 2) \\
44(0 \cdot 3)\end{array}$ & $\begin{array}{l}\text { None } \\
\text { Digoxin, labetalol, thiazide, amiloride }\end{array}$ \\
\hline $45(0 \cdot 3)$ & Digoxin \\
\hline $46(0 \cdot 3)$ & Propranolol, thiazide, potassium supplements \\
\hline & \\
\hline $\begin{array}{l}48(0.4) \\
49(0.4)\end{array}$ & $\begin{array}{l}\text { Metoprolol } \\
\text { Digoxin, frusemide, spironolactone, prazosin }\end{array}$ \\
\hline $50(0.5)$ & None \\
\hline $51(0.5)$ & $\begin{array}{l}\text { Digoxin, metoprolol, nitrates, frusemide, metformin, chlorpropamide, } \\
\text { potassium supplements }\end{array}$ \\
\hline $52(0 \cdot 5)$ & Propranolol \\
\hline $\begin{array}{l}53(0 \cdot 5) \\
54(0.6)\end{array}$ & M.etoprolol, nitrates \\
\hline $55(0.6)$ & Warfarin \\
\hline $56(0 \cdot 6)$ & Propranolol \\
\hline $\begin{array}{l}57(0.7) \\
58(1.0)\end{array}$ & Digoxin, nitrates, bumetanide, potassium supplement, clofibrate \\
\hline $\begin{array}{l}58(1 \cdot 0) \\
59(1 \cdot 0)\end{array}$ & $\begin{array}{l}\text { Nitrates } \\
\text { Digoxin, metoprolol, nitrates, bumetanide, potassium supplements }\end{array}$ \\
\hline $60(1 \cdot 1)$ & Digoxin, propranolol, nitrates, thiazide, amiloride, warfarin \\
\hline $\begin{array}{l}61(1.4) \\
62(1.7)\end{array}$ & Metoprolol, nitrates, amiloride \\
\hline $\begin{array}{l}62(1 \cdot 7) \\
63(1 \cdot 9)\end{array}$ & None \\
\hline $64(2 \cdot 3)$ & $\begin{array}{l}\text { Nifedipine, thiazide } \\
\text { Digoxin, nitrates, thiazide, frusemide, amiloride, potassium }\end{array}$ \\
\hline & Digoxin, nitrates, thiazide \\
\hline $66(2 \cdot 8)$ & $\begin{array}{l}\text { Propranolol, nitrates, frusemide, dipyridamole, potassium } \\
\text { supplements }\end{array}$ \\
\hline $67(4 \cdot 0)$ & None \\
\hline $\begin{array}{l}68(4 \cdot 5) \\
69(5 \cdot 6)\end{array}$ & Labetal \\
\hline $\begin{array}{l}09(3.0) \\
70(15)\end{array}$ & $\begin{array}{l}\text { Propranolol } \\
\text { Atenolol, nitrates, chlorthalidone }\end{array}$ \\
\hline $71(26)$ & None \\
\hline $72(39)$ & Propranolol, prenylamine \\
\hline
\end{tabular}

immune system or lipid metabolism and pharmacodynamic sensitivity.

These findings suggest that routine determination of oxidation status using debrisoquine could be of predictive value in determining perhexiline dosage and controlling its neurotoxicity. Significant associations have already been shown between impaired debrisoquine oxidation and susceptibility to debrisoquine- $\mathbb{D}$ induced postural hypotension ${ }^{39}$; phenacetin-induced methaemoglobinaemia ${ }^{29}$; phenformin-induced changes in blood lactic acid 0 concentrations $^{40{ }^{41}}$; and nortriptyline-induced vertigo, dizziness, and confusional state. ${ }^{42}$ Bertilsson et al found that nortriptyline could be reintroduced successfully at much lower doses in $\overline{0}$ patients with high debrisoquine metabolic ratios. ${ }^{42}$ Our findings suggest that, similarly, perhexiline can be used successfully in the treatment of angina pectoris without any appreciable danger of precipitating peripheral neuropathy provided the dose is tailored to the patient's oxidation status.

We thank the Wellcome Trust for their financial support of this project and to all the physicians who allowed us to study their patients. We also acknowledge the patients' co-operation.

\section{References}

' Armstrong ML. A comparative study of perhexiline, beta-adrenergic blocking agents and placebos in the management of angina pectoris. Postgrad Med f 1973;49,suppl 3:108-11.

2 Dettori AG, Malagnino G, Fatt F, Oriani G. Perhexiline versus prenylamine. A controlled clinical trial in coronary insufficiency. Postgrad Medf $1973 ; 49$,suppl 3:113-4.

${ }^{3}$ Cawein MJ, Lewis RE, Hudak WJ, Hoekenga MT. Clinical evaluation of perhexiline maleate in patients with angina pectoris associated with a positive coronary artery disease index. Postgrad Med $\mathcal{F} 1973 ; 49$, suppl $3: 121-4$.

- Morledge J. Effects of perhexiline maleate in angina pectoris: doubleblind clinical evaluation with ECG-treadmill exercise testing. Postgrad Med f 1973;49, suppl 3:64-7.

5 Sukerman M. Clinical evaluation of perhexiline maleate in the treatment of chronic cardiac arrhythmias of patients with coronary artery disease: Postgrad Med F 1973;49,suppl 3:46-52.

Fleckenstein-Grun G, Fleckenstein A, Byon YK, Kim KW. Mechanisms of action of calcium antagonists in the treatment of coronary disease with special reference to perhexiline maleate. In: International symposium on perhexiline maleate. Amsterdam: Excerpta Medica, 1978:1-22. (Excerpta Medica International Congress series No 424).

‘ Pepine CJ, Schang SJ, Bemiller CR. Alteration of left ventricular responses to ischaemia with oral perhexiline. Postgrad Med $\mathcal{F} 1973 ; 49$, suppl 3:43-6.

${ }^{8}$ Pilcher J, Chandrasekhar KP, Russell RJ, Boyce MJ, Peirce TH, Ikram H. Long-term assessment of perhexiline maleate in angina pectoris. Postgrad Med F 1973;49,suppl 3:115-8.

9 Gitlin N, Nellen M. Perhexiline maleate in the treatment of angina pectoris: a double-blind trial. Postgrad Med $\mathcal{f} 1973 ; 49$,suppl 3:100-4.

10 Gitlin N. Perhexiline maleate in the management of patients with angina pectoris. $S$ Afr Med $\mathcal{F} 1974$;48:904-6.

$"$ Datey KK, Bagri AK, Kelkar PN, Varma SR, Bhootra RK, Amin BM. Perhexiline maleate: a new antianginal drug. Postgrad Med f 1973; 49,suppl 3:75-8.

12 Abaza A, Cattan D, Aziza C, Pappo E. Effets de secondaires mais réversibles à la prise de perhexiline. Nouv Presse Med 1973;2:2820.

${ }^{13}$ Laplane D, Bousser MG, Bouche P, Touboul PJ. Peripheral neuropathies caused by perhexiline maleate. In: International symposium on perhexiline maleate. Amsterdam: Excerpta Medica, 1978:89-96. (Excerpta Medica International Congress series No 424).

14 Newberne JW. Assessment of safety data from patients on short-and longterm perhexiline therapy. Postgrad Med f 1973;49,suppl 3:125-9.

15 Lewis D, Wainwright HC, Kew MC, Zwi S, Isaacson C. Liver damage associated with perhexiline maleate. Gut 1979;20:186-9.

16 Pessayre D, Bichara M, Feldmann G, Degott C, Potet F, Benhamou J. Perhexiline maleate-induced cirrhosis, Gastroenterology 1979;76:170-7.

17 Houdent CE, Wolf LM, Corriat A. Liver during perhexiline hypoglycaemia. Lancet $1977 ; \mathrm{ii}: 1028$.

18 Tomlinson IW, Rosenthal FD. Proximal myopathy after perhexiline maleate treatment. Br Med f 1977;i:1319-20.

${ }^{19}$ Hutchinson WM, Williams J, Cawler J. Papilloedema in patients taking perhexiline maleate. $\mathrm{Br} \mathrm{Med} \mathcal{F} 1978 ; \mathrm{i}: 305$.

20 Atkinson AB, McAreavey D, Trope G. Papilloedema and hepatic dysfunction apparently induced by perhexiline maleate (Pexid). Br Heart $\mathcal{f}$ $1980 ; 43: 490-1$

81 Wright GJ, Leeson GA, Zeiger AV, Lang JF. The absorption, excretion and metabolism of perhexiline maleate by the human. Postgrad Med $\mathcal{f}$ $1973 ; 49$,suppl $3: 8-15$. 
${ }^{22}$ L'Hermitte F, Fardeau M, Chedru F, Mallecourt J. Polyneuropathy after perhexiline maleate therapy. Br Med f 1976;i:1256.

${ }^{23}$ Singlas E, Goujet MA, Simon P. Pharmacokinetics of perhexiline maleate in anginal patients with and without peripheral neuropathy. Eur $\mathcal{f}$ Clin Pharmacol 1978;14:195-201.

${ }^{24}$ Mahgoub A, Idle JR, Dring LG, Lancaster R, Smith RL. Polymorphic hydroxylation of debrisoquine in man. Lancet 1977;ii:584-6.

${ }^{25}$ Sloan TP, Mahgoub A, Lancaster R, Idle JR, Smith RL. Polymorphism of carbon oxidation of drugs and clinical implications. $\mathrm{Br}$ Med 7 1978;ii: 655-7.

${ }^{26}$ Price Evans DA, Mahgoub A, Sloan TP, Idle JR, Smith RL. A family and population study of the genetic polymorphism of debrisoquine oxidation in a British white population. F Med Genet 1980;17:102-5.

27 Sloan TP, Idle JR, Smith RL. Influence of $\mathrm{D}^{\mathrm{H}} / \mathrm{D}^{\mathrm{L}}$ alleles regulating debrisoquine oxidation on phenytoin hydroxylation. Clin Pharmacol Ther $1981 ; 29: 493-7$.

${ }^{28}$ Shah RR, Oates NS, Idle JR, Smith RL. Genetic impairment of phenformin metabolism. Lancet $1980 ; 1: 1147$.

${ }^{29}$ Ritchie JC, Sloan TP, Idle JR, Smith RL. Toxicological implications of polymorphic drug metabolism. In: Environmental chemicals, enzyme function and human disease. (Ciba Foundation Symposium 76). Amsterdam; Excerpta Medica, 1980:219-44.

30 Williams RL, Mamelok RD. Hepatic disease and drug pharmacokinetics. Clin Pharmacokinet 1980;5:528-47.

${ }^{31}$ Weiner M, Chenkin T, Burns JJ. Observations on the metabolic transformation and effects of phenylbutazone in subjects with hepatic disease. Am 7 Med Sci 1954 ;228:36-9.
32 Brodie BB, Burns JJ, Weiner M. Metabolism of drugs in subjects with Laennec's cirrhosis. Med Exp 1959;1:290-2.

${ }^{33}$ Nelson E. Rate of metabolism of tolbutamide in test subjects with liver disease or with impaired renal function. Am f Med Sci 1964 ;248:657-9.

${ }^{34}$ Oldershausen HF von, Held $\mathrm{H}$, Remmer $\mathrm{H}$. Der Abbau von Pentabarbital bei leberschaden. Klin Wochenschr 1970;48:565-7.

${ }^{35}$ Levi AJ, Sherlock S, Walker D. Phenylbutazone and isoniazid metabolism in patients with liver disease in relation to previous drug therapy. Lancet $1968 ; \mathrm{i}: 1275-9$.

${ }^{36}$ Held H, Oldershausen HF von. Zur Pharmakokinetik von Meprobamat bei chronischen Hepatopathien und Arzneimittelsucht. Klin Wochenschr $1969 ; 47: 78-80$

37 Anonymous. Drug metabolism in disease. Lancet $1974 ; \mathrm{i}: 790-1$.

${ }^{38}$ Pollet S, Hauw JJ, Escourolle R, Baumann N. Peripheral-nerve lipid abnormalities in patients on perhexiline maleate. Lancet 1977;i:1258.

39 Idle JR, Mahgoub A, Lancaster R, Smith RL. Hypotensive response to debrisoquine and hydroxylation phenotype. Life Sci 1978;22:979-84.

${ }^{40}$ Idle JR, Oates NS, Shah RR, Smith RL. Is there a genetic predisposition to phenformin-induced lactic acidosis? Br $\mathcal{F}$ Clin Pharmacol $1981 ; 11$ : 418P-9P.

41 Oates NS, Shah RR, Idle JR, Smith RL. Phenformin-induced lactic acidosis associated with impaired debrisoquine hydroxylation. Lancet $1981 ; \mathrm{i}: 837-8$.

42 Bertilsson L, Mellström B, Sjöqvist F, Märtensson B, Äsberg M. Slow hydroxylation of nortriptyline and concomitant poor debrisoquine hydroxylation: Clinical implications. Lancet 1981 ; i :561-2.

(Accepted 6 October 1981)

\title{
Effects of alcohol and smoking on blood lead in middle-aged British men
}

\author{
A G SHAPER, S J POCOCK, MARY WALKER, C J WALE, BARBARA CLAYTON, H T DELVES, \\ LESLEY HINKS
}

\begin{abstract}
A survey of middle-aged men in 24 British towns showed a strong association between blood lead concentrations, alcohol consumption, and cigarette smoking. The association with alcohol persisted after age, social class, body mass index, cigarette smoking, water lead concentrations, and the town of residence had been taken into account. There was an independent but less pronounced association between cigarette smoking and blood lead concentrations after adjustment for the other factors. The possible mechanisms include a decreased excretion of lead due to alcohol-induced hepatic dysfunction and an increased lead intake from cigarette smoking.

These findings have implications for widespread measurement of blood lead concentrations in adults in the community and for all studies attempting to relate blood lead concentrations to environmental exposure.
\end{abstract}

\footnotetext{
Department of Clinical Epidemiology and General Practice, Royal Free Hospital School of Medicine, London NW3 2QG

A G SHAPER, FRCP, FRCPATH, professor of clinical epidemiology

S J POCOCK, MSC, PHD, senior lecturer in medical statistics MARY WALKER, SRN, SCM, research administrator

C J WALE, statistical technician
}

Department of Chemical Pathology and Human Metabolism, University of Southampton, Southampton SO9 4XY

BARBARA E CLAYTON, FRCP, FRCPATH, professor of chemical pathology and human metabolism

H T DELVES, PHD, FRSC, honorary senior lecturer in chemical pathology LESLEY HINKS, FIMLS, senior medical laboratory scientific officer

\section{Introduction}

The British Regional Heart Study seeks to explain the substantial geographical variations in cardiovascular mortality in Great Britain by evaluating the role of environmental, socioeconomic, and personal risk factors. The role of water quality is of particular interest, and analysis of data collected in the study has recently shown that cardiovascular mortality is about $10 \%$ higher in areas with very soft water than in areas with medium-hard water, after appropriate adjustments have been made for other factors such as climate and socioeconomic circumstances. ${ }^{1}$ The mechanism by which soft water is associated with a higher cardiovascular mortality is uncertain but one of the possibilities considered was the increased water lead concentrations seen in many soft, acid waters. ${ }^{2}{ }^{3}$

The Regional Heart Study includes a clinical survey of middle-aged men in 24 British towns, carried out to determine the distribution of established or possible risk factors for cardiovascular disease, to examine their interrelationships and to initiate a long-term prospective study of cardiovascular disease based on these findings. ${ }^{4}$ The survey has included the measurement of blood lead concentrations, and this report describes some relationships observed between blood lead concentration, cigarette smoking, and alcohol consumption in these middle-aged men.

\section{Subjects and methods}

The British Regional Heart Study covers 7735 men aged 40-59 years randomly selected from the age-sex registers of representative general practices in 24 British towns. The criteria for selecting the towns, the general practices, and the subjects as well as the methods of data collection have been presented in a separate report. ${ }^{4}$ In brief, 